the possibility, notwithstanding the conjectural opinions reported by Scarisbrick, McLennan, and McNalty, that the fact of Henry Carey's survival to maturity at all postulates (on the face of the undoubted evidence relevant to the non-surviving births to the King) a further theory that he may actually have been the legitimate son of Sir William Carey and Mary Howard.

Max Skoblo

Department of Psychiatry,

Wembley Hospital,

London NW6

${ }^{1}$ Leslau, J, Ricardian, 1978, 4, 2.

\section{Intraoperative management of phaeochromocytoma with sodium nitroprusside}

SIR, -We read with interest the article by $\mathrm{Dr}$ Peter Daggett and others (29 July, p 311) and would agree with their conclusion that sodium nitroprusside "is a useful hypotensive agent [in the operative management of] patients with a phaeochromocytoma." We would, however, be grateful for an explanation of the rationale behind their choice of $0.5 \mathrm{mg} / \mathrm{kg}$ as a maximum total dose of the drug, as they present no evidence in support of this figure.

Our own studies, ${ }^{1}$ based on data from over 300 patients and many animal experiments in which plasma and red cell cyanide were monitored, lead us to conclude that $1.5 \mathrm{mg} / \mathrm{kg}$ can safely be regarded as a maximum dose for short-term infusion. The apparent arbitrary establishment of such a low limiting dose as $0.5 \mathrm{mg} / \mathrm{kg}$ could possibly lead to a lack of realisation of the full potential of this drug.

John KRAPEZ

Department of Anaesthesia,
St Bartholomew's Hospital,

London EC1

' Cole, P V, Anaesthesia, 1978, 33, 473.

${ }_{*}^{*}$ *We sent a copy of this letter to Dr Daggett and his colleagues, whose reply is printed below.-ED, $B M F$.

SIR,-The maximum dose of sodium nitroprusside (SNP) of $1.5 \mathrm{mg} / \mathrm{kg}$ recommended by Drs Krapez and Cole is the same as that suggested by Vesey $e t$ al $^{1}$ and is applicable to situations where prolonged hypotension is required. In the very particular circumstance of arteriography or operation in cases of phaeochromocytoma, however, episodes of hypertension are usually short-lived. In a 70-kg man the upper limit advised by Drs Krapez and Cole would allow the infusion of $105 \mathrm{mg}$ of SNP "short term." Most phaeochromocytomas are excluded from the circulation within 1-2 $\mathrm{h}$ of starting surgery, and at this point the need to infuse SNP ceases. Thus at the outside the infusion would last for 120 $\mathrm{min}$, and in order to utilise the $105 \mathrm{mg}$ computed above the infusion would have to deliver $875 \mu \mathrm{g} / \mathrm{min}$ for the whole of this time. Vesey and Cole ${ }^{2}$ have observed that the rate of infusion is probably a more important determinant of possible toxicity than the total dose infused, and rates in excess of $800 \mu \mathrm{g} / \mathrm{min}$ are regarded as hazardous. ${ }^{3}$

The preparatory $\alpha$ - and $\beta$-adrenoceptor- blocking regimen described in our paper makes it unnecessary to use duses of this magnitude. A dose of $0.5 \mathrm{mg} / \mathrm{kg}$ in our hypothetical $70-\mathrm{kg}$ man is equivalent to $350 \mathrm{ml}$ of a $0.01 \%$ solution, a volume which is seldom even approached in this situation. To recommend a larger dose would encourage administration at a potentially toxic rate and this could bring into disrepute a drug which we are agreed is invaluable.

Department of Anaesthesia,

Peter DaggetT IAN VERNER

Middlesex Hospital,

London W1

1 Vesey, C J, et al, British fournal of Anaesthesia, 1976, 48, 651.

48, 651.
- Vesey, C J, and Cole, P V V British fournal of

Roche Pharmaceuticals, 115 .

Garden City, Roche Products Ltd. 24 . Welwyn

Copper intrauterine devices in the abdomen

SIR,-Mr P J M Watney's paper (22 July, p 255) prompts me to report an experience with a Copper 7 intrauterine device which supports the belief that these devices, if in the abdominal cavity, should be removed as soon as reasonably possible.

The patient was referred when approximately 18 weeks pregnant in her fourth pregnancy. Two years previously she had had a Copper 7 intrauterine device inserted, and the insertion had been very painful.

The pregnancy continued to term and ended in a normal delivery. The device was not found at the time of delivery, either with the placenta and membranes or in the uterus. A plain abdominal $x$-ray showed the device to be lying above the level of the umbilicus. The patient had requested laparoscopic sterilisation six weeks post partum and this was undertaken, but the device could not be located with the laparoscope.

Formal laparotomy was undertaken and after a prolonged search the device was located high in the small-bowel mesentery, penetrating the wall of the superior mesenteric artery as it emerged under the body of the pancreas. It was removed with great difficulty; after the removal the intima of the vessel was bulging into the cavity left by the device. The wall of the artery was repaired with fine silk sutures and the patient made an uneventful recovery.

This case suggests that the peritoneal cavity's reaction to such a device is more violent than to a non-metal-containing device. In this case it could only have been a matter of atime before erosion into the lumen of the superior mesenteric artery occurred with what could have been catastrophic consequences.

R E ROBINSON

Cambridge

Diflusinal and Stevens-Johnson syndrome

SIR,-Cholestatic jaundice associated with diflunisal therapy has been reported by $\mathrm{Dr}$ Jonathan S Warren (9 September, p 736). We would like to add Stevens-Johnson syndrome as a further probable side effect of diflunisal therapy.

The first patient was an amputee aged 25 treated for pain in her back and remaining knee with $250 \mathrm{mg}$ of diflunisal twice daily. She had been taking Paramol 118 (paracetamol and dihydrocodeine tartrate) for at least thre months, and 10-14 days after the addition of diflunisal to this regimen she became ill with involvement of skin, conjunctiva, and mucous membranes typical of severe Stevens-Johnson syndrome.

The second patient, aged 54 , was receiving $500 \mathrm{mg}$ of diflusinal twice daily for pain related to cervical osteoarthrosis. In addition she had been taking Ferrograd $\mathrm{C}$ (ferrous sulphate and sodium ascorbate) for six months and lorazepam for one month. Two weeks after starting diflunisal she had an exactly similar presentation to the first patient, with conjunctiva, skin, and mucous membrane involvement typical of severe Stevens-Johnson syndrome. In this patient there was also a transient elevation of aspartate and alanine transaminases and creatine kinase. Both patients had a mild thrombocytopenia and a striking feature of both has been the persistence of oral lesions.

Further work is in progress to elucidate the relationship between diflunisal and StevensJohnson syndrome in these cases.

JOHN A HUNTER A J DORWARD ROBIN KNILL-JONES

R T S GUNN

Gartnaval General Hospital, Glasgow

University Department

Rona MaCkie

University Departm,
of Dermatology,
Western Infirmary,

Glasgow

\section{Changing advice on vaccination}

SIR,-As a poor bemused general practitioner struggling to keep abreast of medical progress, I am at a loss to know what recent advances in knowledge prompted the current changes in vaccination procedures.

In 1972 we were told that in view of recent advances in immunological knowledge it was undesirable to immunise infants under 6 months old owing to the incomplete immunity conferred and the risks of side effects. This seemed logical and the revised schedule received general compliance.

In 1978 we are told by the same experts that, following recent changes in knowledge and policy it is now desirable to immunise 3-month-old infants. By what criteria was it judged that the benefits of incomplete immunity conferred on a 3-month-old baby outweigh the risks of possible brain damage, which I would assume to be highest in this age group? Is this new schedule a temporary measure brought in to combat the present pertussis panic and will the experts recommend a return to the old regimen next year? Having weathered the recent wave of anxious mothers asking whether or not their 6-month-old babies should be "done" against whooping cough and having recommended vaccination, I do not relish the prospect of indefinitely immunising the younger age group.

In addition, the Department of Health and Social Security now recommends, after 15 years or more of using oral polio vaccine, that we should discard the remnants of a vial after an immunising session. This raises two important points. Firstly, why has it taken all these years to publicise adequately something which should have been apparent in the early stages of any research programme? And secondly, if the remaining vaccine in a vial is so unreliable are the hundreds of babies and 
children I have unwittingly vaccinated over the past 10 years unprotected against polio? If so, shall we have to reimmunise all these children previously given oral polio vaccine, and if not why all the present fuss?

To jab or not to jab-that is the question. Could we please havc some answers?

\section{Ayr, Strathclyde}

JAMES A BEgG

\section{Thyroid extract}

SIR,-My friend Dr Raymond Greene (16 September, $p$ 832) states that the potency of thyroid extract is very variable and that hypothyroid patients treated with the extract may suddenly become myxoedematous. A far more likely cause for this occurrence than the varying strength of the extract is the patient's failure to take the tablets-compliance, to use the current jargon. Some patients successfully treated with L-thyroxine suddenly become myxoedematous; they have invariably failed to take their tablets.

Patients on replacement L-thyroxine are seen here twice a year or more when serum thyroxine (T4), thyroid-stimulating hormone (TSH), and cholesterol estimations are done. A raised serum cholesterol concentration is often the first evidence that they are failing to take their full thyroid replacement but a raised TSH value is the most reliable check on compliance and the T4 level falls only in the more foolish patients who repeatedly fail to take their tablets.

My obsession with the correct treatment of hypothyroidism must make tedious reading, but I wish to show that patients given adequate replacement over a three-year period do not subsequently develop coronary heart disease de novo.

Charing Cross Hospital,
London W6

P B S FOWLER

\section{Propranolol for acute migraine}

SIR,-During the past few years more and more notice has been taken of the adverse effects of ergotamine. The value of propranolol in the prophylactic treatment of the migraine syndrome has been established ${ }^{1-4}$; there has also been a case report of severe cluster headache treated with propranolol.5

We studied the effect of propranolol on acute attacks of migraine in an open trial with 30 patients in the Mehiläinen Migraine Clinic in Helsinki. The series consisted of 26 women and four men. The mean age was 36.4 years, with a range of 16 to 63 years. Nineteen patients suffered from common migraine and 11 from classic migraine. A single dose of propranolol was $40 \mathrm{mg}$; in 15 cases the total dose was $40 \mathrm{mg}$, in 14 cases $80 \mathrm{mg}$, and in one case $120 \mathrm{mg}$. Seventeen of the attacks studied were classified as severe, 11 moderate, and two mild. Excellent or good response to the medication was observed in $16(53.3 \%)$ of the patients. Seven patients of this group became totally painless and nine had only mild symptoms at the end of an observation period of two hours. Nausea, which occurred in 19 cases, became less severe or stopped in 12 of these $(63.2 \%)$. Vomiting, which occurred in 11 cases, was relieved in seven $(63.6 \%)$. Sensitivity to light was reduced or stopped in
12 of 26 persons $(46 \cdot 1 \%)$. In the subjective evaluation $71 \%$ of the patients formerly treated with ergotamine found propranolol better than or as good as ergotamine; more than half of them preferred propranolol. No serious adverse reactions were observed and 27 patients showed no side effects whatsoever.

This pilot study gives some evidence of the therapeutic value of propranolol in treating acute attacks of migraine; what we now lack are controlled studies.

Department of Neurology,
University of Helskinki

RIITTA Tokola

Department of Neurology,

1 Weber, R B, and Reinmuth, O M, Neurology, 1972 ,

22, 366.
Widerøe, T-E, and Vigander, T, British Medical Fournal, 1974, $2,699$.

Forssman, B, et al, Headache, 1976, 16, 238

Stensrud, P, and Sjaastad, O, Acta Neurologica Scandinavica, 1976, 53, 229.

Fogelholm, R, British Medical fournal, 1972, 4, 110.

\section{Indwelling pericardial catheter in} cardiac tamponade

SIR,-I read with much interest the report by Dr M Dancy and others (14 January, p 79), in particular the method of inserting a catheter into the pericardium in the management of cardiac tamponade following perforation of the myocardium by a pacing electrode. I have subsequently used this method in treating a 66-year-old man who developed a haemopericardium following a large anterior myocardial infarct.

Under image intensifier control a soft catheter (Vyflon Desilet FGO5) was introduced into the pericardium by the xiphisternal route and its location confirmed with $5 \mathrm{ml}$ of Conray solution. With a two-way tap intermittent aspiration (judged by central venous pressure measurement) was performed over a three-week period and a total of $840 \mathrm{ml}$ of blood was recovered from the pericardial sac. The objective was that of supportive management until definitive surgery could be undertaken

Unfortunately, three weeks after admission to hospital the patient suffered a fatal cardiac arrest. Necropsy showed an old inferior myocardial infarct and a recent anterior infarct with extravasation of blood through the infarcted muscle. There was some residual blood in the pericardia cavity and some clot loosely adherent to the inferior heart surface.

The method of insertion of a catheter into the pericardium is relatively easy when the Seldinger wire technique is used and is made easier under image intensifier screening. The catheter may then be secured to the skin and aspiration performed by intensive treatment unit staff. It precludes the necessity of repeated needle aspiration (with its inheren dangers) and thereby spares the patient much distress.

Redhill General Hospital, Redhill, Surrey

\section{Paracetamol poisoning}

SIR,-The period covered by the 1975 Mortality Statistics and discussed by Dr T J Meredith and others (12 August, p 478) overlaps with that of the recently published North-east Regional Paracetamol Overdose Survey. ${ }^{1}$ In this we found a mortality due to consequent hepatic necrosis of $3.5 \%$ in 201 patients referred over the 12 -month period
November 1974-November 1975. We also extrapolated our local incidence to find a total UK annual figure of 6000 cases of overdose, an estimate similar to that of an earlier publication. ${ }^{2}$ When these rates are applied to just England and Wales we find an estimated mortality of 185 , quite close to the official figure of 212 deaths.

Although the fallibility of this approach is obvious, it suggests that the methodology devised by Mr J G Harvey and Dr J B Spooner (16 September, p 832) has resulted in an underestimate of true mortality due to paracetamol. It may be noted that a significant proportion of our patients were alcoholic or psychiatrically afflicted in such circumstances that their deaths would be recorded under other headings in official figures. Furthermore, the majority of our deaths occurred in patients referred too late, up to $48 \mathrm{~h}$ after the overdose, for treatment to be effective. The contribution of delay to mortality is thus significant. How then may 84 deaths before hospital admission be totally excluded?

ADrian N HAMLYN

University Medical Clinic,

Tübingen, Germany

1 Hamlyn, A N, Douglas, A P, and James, O, Postgraduate Medical fournal, 1978, 54, 400. Proudfoot, A T, and Wright, V N, British Medical
fournal, 1970, 3, 557 .

\section{Razoxane in treatment of acute} myeloid leukaemia

SIR,-Dr $M$ Bhavnani and his colleagues (16 September, p 801) conclude that treatment with oral razoxane (125 $\mathrm{mg}$ three times daily) along with a low dose of cytarabine $(1 \mathrm{mg} / \mathrm{kg}$ day intravenously) is not satisfactory in acute myeloid leukaemia (AML). This is in contrast to the preliminary report by Hellmann and his associates. ${ }^{1}$ We should like to contribute additional information from a small series.

We have used this regimen in the treatment of seven consecutive, previously untreated adults with AML aged 17-67 years; at the time of diagnosis the haematological values were in the following ranges: haemoglobin $4 \cdot 2-10 \cdot 6 \mathrm{~g} / \mathrm{dl}$, leucocyte count $5-157 \cdot x$ $10^{9} / 1 \quad\left(5000-157000 / \mathrm{mm}^{3}\right)$, platelets $<50$, $80 \times 10^{9} / 1\left(<50000-80000 / \mathrm{mm}^{3}\right)$. Both drugs were given daily for three days and the course repeated at intervals of 10 days. One patient died five days after starting treatment and there was gross leukaemic infiltration of all organs at post-mortem. The other six all went into good partial remission after 2-4 courses; there were no blast cells in the peripheral blood film and clinically the patients were well. One patient relapsed after six months and died within five days of overwhelming sepsis. A further patient died after six weeks from an apparently unrelated cause. The other four are alive and well after 10, 14, 26 , and 32 weeks. In marked contrast to the findings of Dr Bhavnani and his colleagues our patients were not troubled by nausea and vomiting and there were no haemorrhagic or infective complications except those present at the time of diagnosis.

Recently complete remission rates of $79^{\circ} \%$ and $85 \%$ have been achieved with combinations of daunorubicin, cytarabine, and thioguanine (DAT), ${ }^{2}$ but the problem of the maintenance of remission has not been solved and the mean survival times in these studies were 54 and 70 weeks. Clearly clinical trials involving aggressive chemotherapy and the 